\title{
QUE POLÍTICA PÚBLICA PARA \\ A AGRICULTURA FAMILIAR NO SEGUNDO \\ GOVERNO LULA?
}

\author{
Eric Sabourin*
}

Resumo: O governo Lula da Silva manteve a prioridade dos meios a favor do agronegócio brasileiro, apesar do aumento importante dos recursos destinados à agricultura familiar e camponesa. Como explicar o que, à primeira vista, parece uma contradição e, sobretudo, a que debates respondem essas posições no seio do governo federal? $\mathrm{O}$ artigo analisa as tensões, avanços e impasses do primeiro governo Lula em matéria de política de agricultura familiar e desenvolvimento rural a partir da aplicação dos seus principais instrumentos: o Programa Nacional de Fortalecimento da Agricultura Familiar e o Programa de Desenvolvimento Sustentável dos Territórios Rurais.

Palavras-chave: Brasil, globalização, governo Lula, políticas públicas, agricultura familiar, desenvolvimento rural.

\section{Introdução}

Em matéria de agricultura e de desenvolvimento rural, o presidente Luis Inácio Lula da Silva foi eleito na base de um importante programa de reforma agrária, de defesa da agricultura familiar e de luta contra a pobreza no campo. Nomeou como ministros da Agricultura, do Desenvolvimento e do Comércio,

\footnotetext{
Sociólogo do Centro de Cooperação Internacional em Pesquisa Agronômica para o Desenvolvimento (CIRAD), Unidade de Pesquisa "Actions collectives, politiques publiques et marchés"; pesquisador visitante do CNPq, professor visitante no Departamento de Sociologia da Universidade de Brasília (UnB). E-mail: sabourin@cirad.fr
}

Artigo recebido em 12 jan. 2007 e aprovado em 23 abr. 2007. 
três grandes proprietários também patrões de agroindústrias, os quais adotaram uma política a favor da agricultura patronal e de apoio às exportações agrícolas, particularmente agressiva. Foram amplamente apoiados pelo Ministério das Relações Exteriores que foi a origem da criação do grupo dos 21 nas últimas rodadas da Organização Mundial do Comercio (OMC). A dualidade da política agrícola brasileira introduzida pelo segundo governo Cardoso foi assim mantida, institucionalizada e até exacerbada, pelo menos nos discursos.

A agricultura familiar (4,2 milhões de estabelecimentos e $70 \%$ da população ativa agrícola) está administrada pelo pequeno Ministério do Desenvolvimento Agrário (MDA) e a agricultura empresarial (550.000 estabelecimentos, ou seja $12 \%$ do total para $70 \%$ das terras agrícolas) pelo potente Ministério da Agricultura, da Pesca e da Alimentação (MAPA) (FAO-Incra, 2000).

Ainda que os créditos para a agricultura familiar tenham aumentado muito e sejam distribuídos segundo diversas modalidades, apenas representam de $15 \%$ a $20 \%$ daqueles destinados à agricultura patronal. $\mathrm{O}$ mais surpreendente é que essa visão hegemônica do sucesso do agribusiness, ${ }^{1}$ politicamente construída pela bancada ruralista conservadora, conseguiu introduzir efeitos perversos de inspiração neoliberal no seio dos programas principais do governo Lula para o campo, embora controlados pelo Partido dos Trabalhadores (PT): segurança alimentar (Fome Zero), reforma agrária e apoio à agricultura familiar. Proponho a hipótese de que o PT e seus aliados nos movimentos sociais não dispunham de propostas alternativas sólidas ao modelo neoliberal. Essa carência vem do desconhecimento da realidade diversa da agricultura familiar e camponesa brasileira. Pode estar também ligada a laços ideológicos ou corporativistas com modelos de políticas públicas estatizantes e irrealistas ou mal adaptados. De fato, os debates que marcaram o primeiro Governo Lula sobre esses temas, passaram, 
em parte, ao largo das verdadeiras questões. Mesmo assim, podem ser identificados os três principais debates em matéria de política de desenvolvimento rural no seio do MDA e do governo Lula, que podem ser associados aos grandes programas tocantes à agricultura familiar manejados respectivamente pelas três secretarias do MDA.

Quanto ao Programa Nacional de Fortalecimento da Agricultura Familiar (Pronaf), administrado pela Secretaria da Agricultura Familiar (SAF), o debate gira em torno de duas teses, ao meu ver redutoras, parciais e que ignoram alternativas vivas existentes país adentro. Uma tese passa pela promoção de um agricultor familiar inovador e pequeno empresário, cada vez mais integrado ao mercado internacional ou a nichos de mercados segmentados por meio da qualificação dos produtos. A outra tese considera que o desenvolvimento do capitalismo agrícola e o grau de globalização da agricultura brasileira tornaram-se tais que a solução da reforma agrária e do apoio à agricultura camponesa está superada, tanto do ponto de vista dos interesses da burguesia capitalista como das forças produtivas. Nunca permitirá a instalação de pequenos produtores competitivos, porém pode se justificar como política social de combate à pobreza, de re-socialização das populações rurais desarraigadas ou excluídas do campo pela modernização da agricultura. Essa tese aproxima-se muito da visão neoliberal do setor do agribusiness e se reencontra na parte rural do programa Fome Zero.

Esse debate se prolonga a propósito do recém-criado Programa de Desenvolvimento Sustentável dos Territórios Rurais (PDSTR), conduzido pela Secretaria do Desenvolvimento Territorial (SDT). Esse programa tem por objetivo favorecer um desenvolvimento regional integrado mediante a definição participativa de projetos de infra-estrutura coletivos entre os diferentes ministérios, serviços dos Estados locais, municípios e sociedade civil, a partir de um apoio prioritário ao segmento da agricultura familiar. 
O Plano Nacional de Reforma Agrária (PNRA) foi confiado à Secretaria da Reorganização Agrária (SRA), que administra o Instituto Nacional de Colonização e de Reforma Agrária (Incra) e não é objeto deste artigo.

Para tratar dos debates sobre o papel e o modelo de agricultura familiar no início do segundo governo Lula, a primeira parte do artigo lembra o quadro da agricultura brasileira e mostra a importância da contribuição oculta da agricultura familiar e camponesa para a produção nacional. Analisa as evoluções do Pronaf e do PDSTR e os avanços e limites do seu papel de políticas integradoras. A segunda parte levanta a questão da ambigüidade de um modelo dominante de apoio a uma agricultura familiar em realidade muito diversa que tende a reduzir a alternativa entre integração forçada ao mercado capitalista e à assistência social.

\section{Agricultura empresarial versus agricultura familiar}

O Brasil institucionalizou desde 1998 uma abordagem dualista do seu setor agrícola separando o apoio à agricultura familiar com a criação do MDA, do apoio à agricultura patronal, mantido mediante o MAPA.

Essa medida apenas cristalizou a representação já forte no seio do governo e da sociedade de uma agricultura a duas velocidades: uma agricultura capitalista empresarial e uma pequena produção de subsistência, camponesa e atrasada. Essa visão foi fortalecida pela oposição cada vez mais radical, institucionalizada no seio do Estado e mantida pela mídia, entre uma agricultura capitalista competitiva e provedora de divisas (qualificada de agronegócio por referência ao agribusiness americano) e uma agricultura familiar associada à reforma agrária e a compensações sociais custosas para o contribuinte. 


\section{A importância oculta da agricultura familiar e camponesa}

As estatísticas oficiais, apesar do seu atraso (IBGE, 1996) e dos seus limites que tendem a reduzir a importância da produção familiar (não levam em conta o auto-consumo, o intra-consumo e a distribuição não mercantil e não monetária, não registram as estruturas muito pequenas de minifúndio, etc.), desmentem radicalmente essa imagem economicamente falsa e politicamente construída da realidade agrícola do Brasil.

Para um total de 4.900.000 estabelecimentos (Tabela 1), $4.150 .000(85 \%)$ correspondem ao setor familiar e camponês e $550.000(12 \%)$, ao setor patronal. Mas a agricultura familiar responde por $38 \%$ da produção agrícola nacional, ocupa $75 \%$ da população ativa agrícola (Tabelas 2 e 3) quando só se beneficia de $30 \%$ da superfície agrícola e de $25 \%$ dos financiamentos públicos destinados ao conjunto do setor (IBGE,1996; FAO-Incra, 2000).

A agricultura familiar e camponesa está presente em todas as grandes produções destinadas ao mercado interno ou à exportação: contribui com dois terços da produção de tubérculos e de leite, um terço da produção de soja, $20 \%$ da de carne bovina e as frutas, o fumo, a laranja, o cacau, a pimenta-do-reino são também produções camponesas no Brasil. A produção dos estabelecimentos onde o trabalho assalariado domina apenas ganha para a cana-de-açúcar, a soja, o arroz e a pecuária bovina (FAO-Incra, 2000).

O Nordeste, a região "problema" da modernização brasileira, reúne praticamente a metade dos estabelecimentos familiares e camponeses que conseguem produzir $43 \%$ do PIB agropecuário da região, mobilizando apenas $40 \%$ da superfície e $27 \%$ dos financiamentos públicos. A produtividade por hectare é, portanto, superior à média nacional, mas, sobretudo àquela das grandes fazendas da região (pecuária extensiva e cana-de-açúcar). 


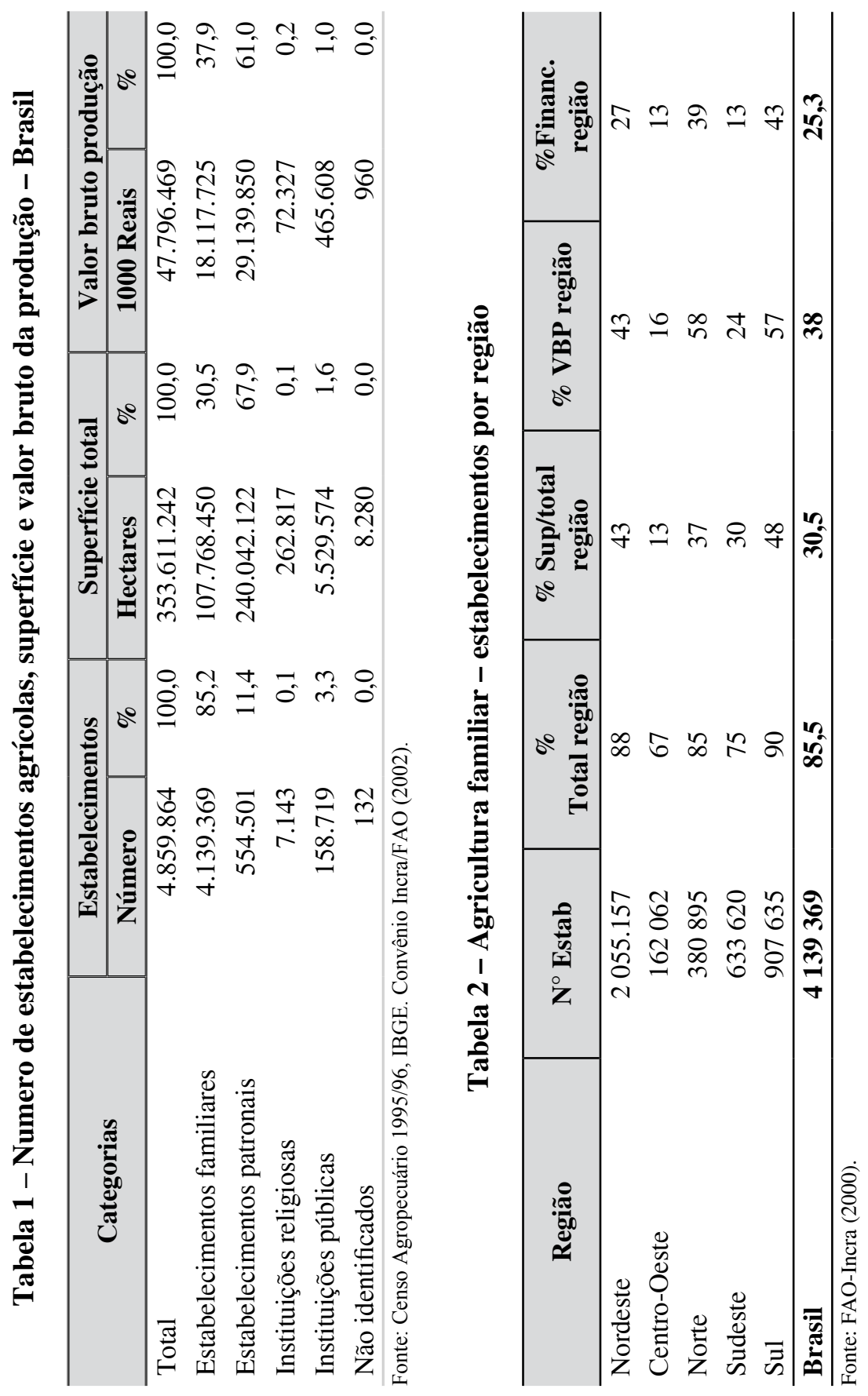




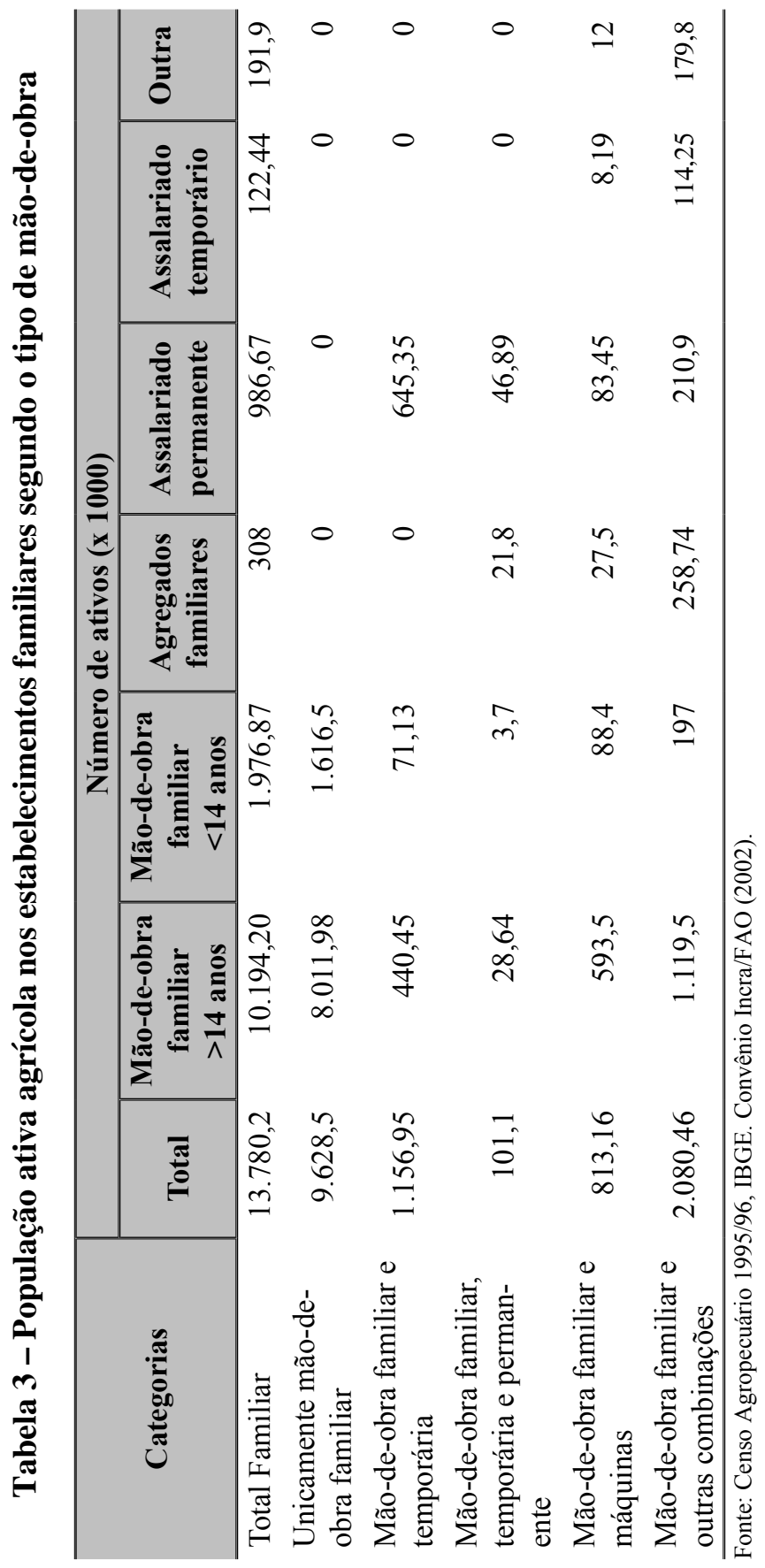


De fato, o setor agrícola brasileiro no seu conjunto é dinâmico e essencial para a economia nacional: representa $33 \%$ do PIB, $42 \%$ das exportações totais e $37 \%$ dos empregos. O PIB agrícola brasileiro foi de US\$ 180,2 milhões em 2004 e 165,5 milhões em 2005. Entre 1998 e 2003, a taxa de crescimento do PIB agrícola foi de 4,67\% /ano. Em 2005, as exportações agrícolas renderam US\$ 36 milhões, com um superávit de US\$ 25,8 milhões. Portanto, as estatísticas oficiais mostram que o setor familiar e camponês assegura $40 \%$ do PIB agrícola do país, quando só tem acesso a $25 \%$ das terras e dos financiamentos públicos.

Se a mecanização se difundiu pouco na agricultura familiar, por razões de estrutura fundiária reduzida ou dividida, ela usa adubos e pesticidas, o que lhe permite obter rendimentos equivalentes àqueles da agricultura patronal. À visão falsa de uma agricultura familiar descrita como um setor pouco produtivo, limitado ao abastecimento do mercado local, pode-se opor o fato de que produz bem mais do que a agricultura patronal por hectare cultivado, e que ocupa sete vezes mais mão-de-obra.

Se fossem retirados os estabelecimentos familiares muito pequenos que, em realidade, escondem o assalariamento (a pluriatividade) ou o desemprego rural, os números seriam ainda mais expressivos: os estabelecimentos de 20 a 100 hectares produzem tanto quanto o conjunto da agricultura patronal, com 2,5 vezes menos terra.

Avanços e limites dos programas especificos para a agricultura familiar

Graças à influência dos movimentos sociais sindicais na política do MDA, os recursos destinados ao apoio da agricultura familiar são cada vez mais significantes. Os créditos do Pronaf 
nunca forma tão importantes desde a sua criação, com resultados positivos em termos de aumento da produção e da renda (Tabela 4 e Gráfico 1).

Esses recursos permitiram consolidar as unidades familiares menos precárias, pois com os tetos de crédito (A, B, C, D, E, etc.) por categoria de patrimônio, o sistema não favorece a progressão das unidades menores.

As diversas avaliações reconhecem que o Pronaf, sob a forma de crédito individual ou de subvenção para equipamentos coletivos, beneficiou sobretudo os agricultores familiares mais dotados de capital e melhor articulados com a rede bancária, essencialmente nos Estados do Sul (Abramovay \& Veiga, 1999; Abramovay \& Piketty, 2005; Carneiro, 1997; Ibase, 1999).

O impacto reduzido em termos de número de contratos ou de apoio à produção registrado no Norte e no Nordeste levou o governo Lula a diversificar as modalidades de crédito (jovens, mulheres, semi-árido, floresta, agroecologia, transformação dos produtos, etc.). Mesmo assim - e até para os agricultores mais pobres - , trata-se sempre de apoio a uma produção destinada ao mercado capitalista. Nenhuma medida foi contemplada para fortalecer estratégias de autoconsumo, de venda direta ou para a implementação de mercados locais de proximidade ou ainda de circuitos curtos entre produtores e consumidores.

Os esforços de diversificação das modalidades de crédito não correspondem a uma análise da diversidade da natureza e dos modos de produção das agriculturas familiares e camponesas. Eles se traduzem por duas tendências: i) uma segmentação em função do patrimônio com um teto de crédito por tipo de produtor (mais ou menos precário, mais ou menos integrado ao mercado); ii) uma segmentação por categoria de público-alvo (mulheres, jovens, etc.) que arriscam dividir - em vez de fortalecer - a coesão da unidade familiar. 
Tabela 4 - Número de contratos e volume do crédito Pronaf - por ano fiscal - 1999/2006

\begin{tabular}{c|r|r}
\hline Ano & \multicolumn{1}{c|}{ Contratos } & \multicolumn{1}{c}{ Valor (R\$ 1,00) } \\
\hline 1999 & 802.849 & $1.829 .731 .597,98$ \\
2000 & 969.727 & $2.188 .635 .003,31$ \\
2001 & 910.466 & $2.153 .351 .258,79$ \\
2002 & 953.247 & $2.404 .850 .769,99$ \\
\hline Total Governo Cardoso II & $\mathbf{3 . 6 3 6 . 2 8 9}$ & $\mathbf{8 . 5 7 6 . 5 6 8 . 6 3 0 , 0 7}$ \\
\hline 2003 & 1.138 .112 & $3.806 .899 .245,48$ \\
2004 & 1.611 .463 & $5.761 .475 .996,11$ \\
2005 & 1.671 .183 & $6.404 .190 .129,32$ \\
2006 & 1.372 .361 & $5.572 .532 .232,47$ \\
\hline Total Governo Lula I & $\mathbf{5 . 7 9 3 . 1 1 9}$ & $\mathbf{2 1 . 5 4 5 . 0 9 7 . 6 0 3 , 3 7}$ \\
\hline
\end{tabular}

Fontes: BACEN, BANCOOB, BANSICREDI, BASA, BB, BN E BNDES (2006)

Disponível em: www.mda.gov.br/saf/pronaf

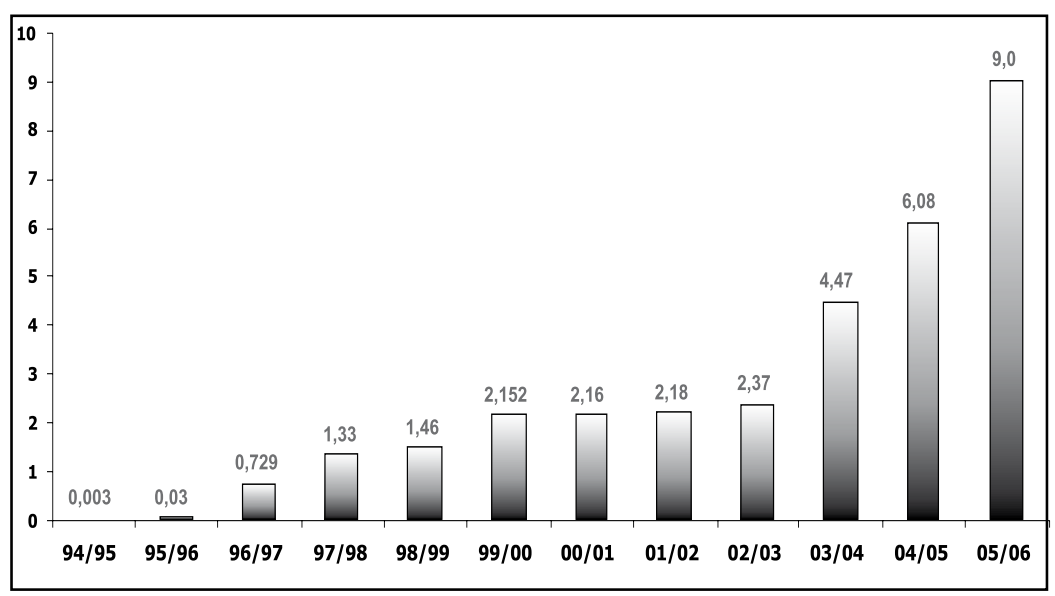

Gráfico 1 - Evolução dos créditos para agricultura familiar de 1994/95 a 2005/06 (bilhões de Reais)

Fonte: SAF/MDA (2006). 
Diferenciação dos instrumentos e flexibilidade das políticas não quer dizer segmentação entre públicos e medidas separados. Essa segmentação, que pouco propicia a legibilidade das orientações e prioridades pelos beneficiários ou pela sociedade, foi exacerbada no governo Lula pela repartição dos cargos. Se os ministérios da Agricultura, da Indústria e Comércio e do Desenvolvimento foram confiados a grandes proprietários, agroexportadores de álcool, açúcar, bovinos e aves, o ministério encarregado da agricultura familiar não escapou à regra.

As três secretarias do MDA confiadas ao Partido dos Trabalhadores foram repartidas entre responsáveis e equipes vindos dos movimentos e organizações sindicais e profissionais, concorrentes entre elas ou ligadas a correntes diferentes do PT: a SRA à Contag, a SAF à Federação dos Trabalhadores da Agricultura Familiar (Fetraf), o Incra ao Movimento dos Trabalhadores Sem Terra (MST) e a SDT às cooperativas da agricultura familiar. Mesmo se o acesso à gestão das políticas públicas de quadros vindos dos movimentos sociais constitui uma tentação, esse tipo de repartição apresenta limitações. Primeiro, pode-se discutir se isso permite ao governo federal assegurar a condição de uma política pública de maneira neutra ou se deixa margem para negociar em situação de arbitragem e de garantia de princípios e prioridades. Segundo, o mais preocupante é o aparecimento de viesses corporativistas na medida em que esses movimentos estão em concorrência para constituir suas bases sociais e para mobilizar mais recursos. Terceiro, além da concorrência entre programas do mesmo ministério destinados ao mesmo público, cada secretaria tem uma tendência natural a impor o seu modelo de desenvolvimento da agricultura familiar. Existe, portanto um risco sério de ver coexistir, em tensão, três políticas parciais em lugar de uma só, declinada de maneira diversa e flexível, em função das situações ou a partir de verdadeiras negociações técnicas com os representantes regionais e locais dos agricultores familiares. 
Qual deveria ser, em, princípio, o papel da abordagem territorial, global e destinada a coordenar os diferentes enfoques setoriais a partir da realidade dos meios e dos atores locais? O que há de novo no Brasil em relação à abordagem territorial em matéria de desenvolvimento rural?

\section{A abordagem territorial: mutação ou apenas renovação do discurso?}

A abordagem territorial e participativa proposta no governo anterior (Incra, 1999; Sabourin et al., 2005) foi retomada e ampliada pelo governo Lula (MDA, 2003). A negociação e a gestão de projetos territoriais sustentáveis fundam-se na implementação de mecanismos de interação entre a ação pública do Estado e a ação coletiva das populações rurais por meio dos conselhos de desenvolvimento sustentável.

\section{Um enfoque pertinente, mas exigente}

No papel, a justificativa teórica e metodológica do Programa de Desenvolvimento Sustentável dosTerritórios Rurais (PDSTR) é muito atraente e pertinente, pois procura construir bases mais humanas para o desenvolvimento econômico a partir de valores éticos de eqüidade, justiça, respeito, co-responsabilidade e para o reconhecimento da multifuncionalidade dos espaços rurais (Box 1).

A abordagem territorial deve contribuir para constituir espaços de diálogo entre organizações locais, sociedade civil, municípios e serviços do Estado de maneira a levar em conta as dinâmicas locais, as prioridade e especificidades dos atores locais. De acordo com a proposta do MDA, o desenvolvimento territorial poderia ser a base espacial e rural para uma política de desenvolvimento sustentável. Resultaria da "capacidade dos múltiplos atores de um território a se coordenar, a definir juntos orientações e a implementar os meios 
para atingi-las" (Brasil. MDA, 2003, 2005). O desenvolvimento territorial seria, assim, o resultado da interação entre dinâmicas sociais e produtivas locais e dinâmicas institucionais. Um dos principais desafios seria fortalecer a capacidade dos atores da agricultura familiar para contribuir de maneira ativa à definição e implementação de projetos e de instrumentos de políticas públicas territorializadas.

\section{Box 1: A visão do desenvolvimento territorial do MDA (2004)}

O MDA justifica a abordagem territorial do desenvolvimento rural por quatro razões:

- o rural não se limita ao agrícola.

- a escala municipal é reduzida demais para o planejamento e a organização do desenvolvimento e aquela do Estado é demasiado ampla para levar em conta a heterogeneidade das especificidades locais;

- é necessário descentralizar as políticas públicas atribuindo competências aos espaços e atores locais;

- o território é a unidade que melhor permite tomar em consideração e mobilizar os laços de proximidade entre indivíduos, grupos sociais e instituições;

A abordagem territorial deve criar as condições para que os agentes locais se mobilizem em torno de uma visão de seu futuro, de um diagnóstico de suas potencialidades e limitações e dos meios para perseguir seu próprio projeto de desenvolvimento sustentável.

Deve considerar a interação entre os sistemas socioculturais e os sistemas ecológicos, a integração produtiva e a valorização competitiva dos recursos que permitam a cooperação e a co-responsabilidade dos atores sociais; trata-se de mobilizar os valores de eqüidade, de respeito à diversidade, de solidariedade, de justiça e de inclusão social. Esses valores dependem do reconhecimento da multifuncionalidade das dimensões que contribuem para o futuro de um território:

-Dimensão econômica: capacidade de inovação, de diversificação, de articulação dos recursos locais, de integração das redes de pequenas empresas;

- Dimensão sociocultural: eqüidade social por meio da participação cidadã nas estruturas de poder a partir do respeito dos valores e da cultura do território e pela melhoria da qualidade de vida da populações;

-Dimensão político institucional: institucionalidades renovadas, governabilidade democrática e promoção do exercício da cidadania;

- Dimensão ambiental: os recursos naturais como ativos do desenvolvimento; sustentabilidade para as gerações futuras.

Fonte: www.mda.gov.br 
Nesse quadro, 108 territórios prioritários foram identificados pelo MDA, que oferece um apoio metodológico para a implementação de planos de desenvolvimento territorial que devem orientar os financiamentos de infra-estruturas e equipamentos intermunicipais, destinados a fortalecer o desenvolvimento rural e a agricultura familiar (Gráfico 2 e Tabela 5).

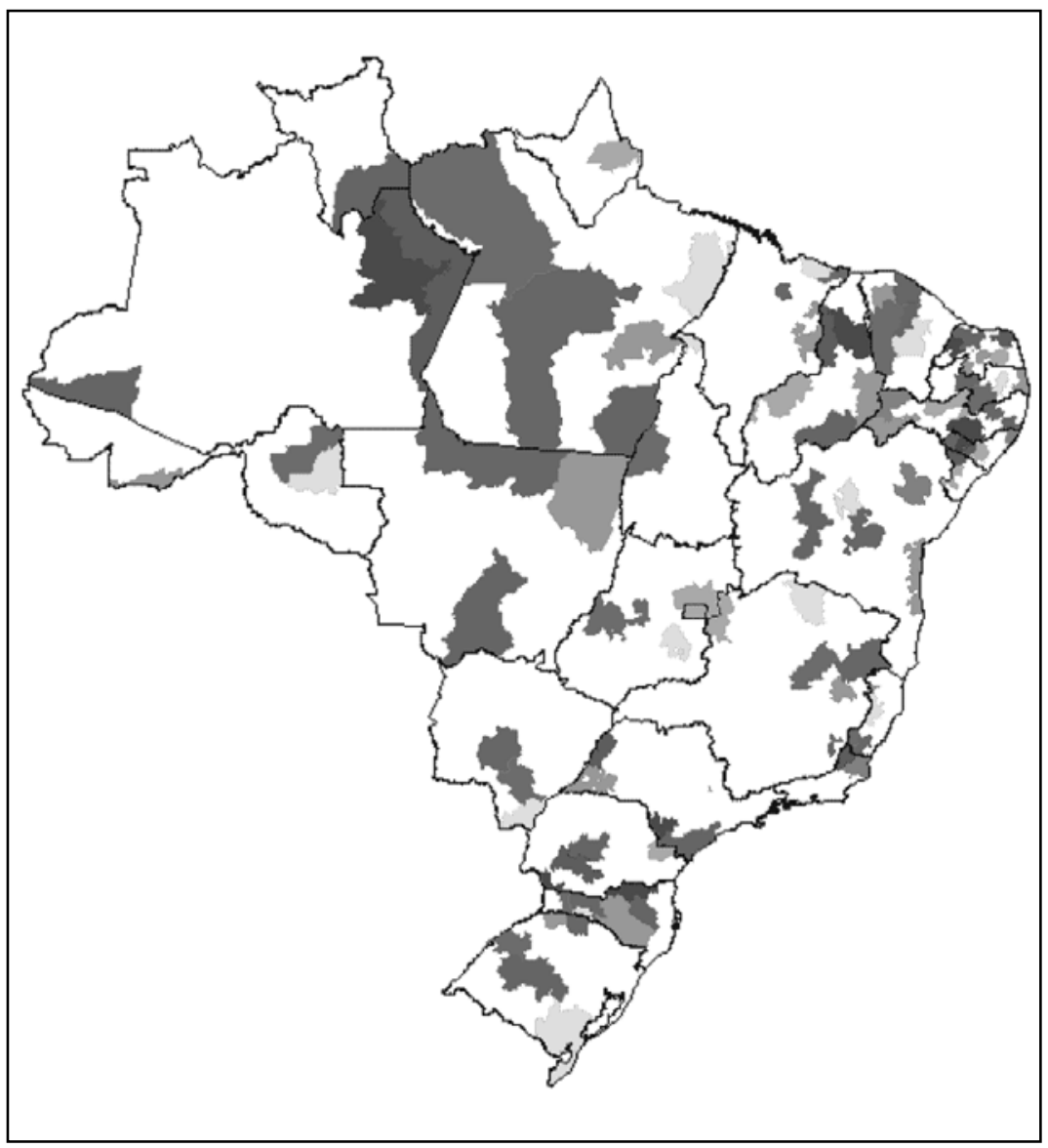

Gráfico 2 - Territórios homologados pelo MDA-SDT - 2005 


\section{Tabela 5 - Territórios rurais homologados pela Secretaria de Desenvolvimento Territorial (SDT) - 2005}

\begin{tabular}{l|c|c}
\hline \multicolumn{1}{c|}{ Macrorregião } & Territórios & Municípios \\
\hline Norte & 16 & 137 \\
Nordeste & 45 & 718 \\
Centro-Oeste & 9 & 128 \\
Sudeste & 18 & 303 \\
Sul & 16 & 386 \\
\hline Total & $\mathbf{1 0 4}$ & $\mathbf{1 . 6 7 2}$ \\
\hline
\end{tabular}

Fonte: MDA/SDT (2005).

\section{Uma institucionalização em curso}

O Programa de Desenvolvimento Sustentável dos Territoriais Rurais (PDSTR) tenta federalizar um apoio estrutural da agricultura familiar na continuidade do Pronaf infra-estrutura. Para o MDA, ao mesmo tempo, trata-se de inovar institucionalmente com relação às políticas agrícolas anteriores (com projetos negociados pela sociedade civil organizada, num quadro territorial, etc.) e, politicamente, ao tentar contornar as autoridades dos Estados e municípios, toda poderosas em matéria de execução dos programas, em virtude da subsidiaridade do sistema federal.

De fato, esse processo de territorialização do desenvolvimento por meio de projetos geoeconômicos, não é completamente novo no Brasil. Continua e fortalece o Pronaf Infra-estrutura, conta com antecedentes em: a) desenvolvimento rural integrado (DRI) específico para a agricultura familiar, como o PAPP no Nordeste; b) desenvolvimento regional territorializado (Conselhos Regionais de Desenvolvimento (Corede), do Rio Grande do Sul); c) gestão de recursos pelos municípios e com a participação dos produtores rurais (APR Nordeste, apoiado pelo Banco Mundial mediante o sistema de Community Driven Development). Portanto, o PDSTR prolonga um processo de institucionalização da participação 
da população rural por meio da sociedade civil organizada e da representação dos agricultores familiares. Pode, assim, ser atribuído ao PDSTR o fortalecimento da emergência de uma nova geração de lideres técnicos nos serviços públicos e nas ONGs e de dirigentes das comunidades e organizações de agricultores familiares e camponeses. Precisamente, se o processo de elaboração, discussão e avaliação colegiada de projetos intermunicipais consegue funcionar, é graças a esses novos lideres que não foram ainda cooptados ou corrompidos pelo sistema clientelista tradicional.

No entanto, e segundo os próprios responsáveis do MDA/SDT, esses territórios, cujos contornos foram, em boa parte, desenhados por decisões dos municípios e dos Estados, têm geralmente pouca identidade e um reconhecimento fraco por parte dos agricultores, dos atores econômicos e ate dos políticos.

Por certo, a descentralização não se realiza por decreto. A experiência mostra que se a sociedade civil e o setor privado, estão mais acostumados a relações horizontais, o Estado e seus serviços encontram problemas para abandonar o eixo de decisão vertical. Ora os contornos e a definição da maioria dos territórios apoiados foram propostos pelo MDA em Brasília, mas decididos pelos Conselhos de Desenvolvimento Rural e pelos governos dos Estados e dos municípios em relação com alguns interlocutores locais, geralmente a partir de considerações políticas ou sindicais. A população interessada não foi consultada e, em muitos casos, ela ignora ainda até a existência do território ou do projeto de território após alguns anos. De fato, o processo de territorialização está sendo contrariado ao mesmo tempo pela concepção de pequenos projetos locais e pela natureza do sistema federal, em particular pelos canais de financiamento e de implementação das infra-estruturas e equipamentos, que só podem passar pelos Estados ou municípios. $\mathrm{O}$ investimento previsto pelo MDA para acompanhar a construção de processos de identidade territorial é, louvável, mas continuará, sem dúvida, tendo de enfrentar esses problemas estruturais. 


\section{Uma territorialização limitada}

O primeiro freio à territorialização dos projetos apoiados pelo PDSTR é relativo ao tamanho dos territórios (10 a 20 municípios) e a uma exigência de mudança de escala com relação à gestão municipal. A nova escala parece estranha se comparada com as práticas e representações dos atores políticos e econômicos, e, muitas vezes, revela-se pouco adaptada para apoiar as dinâmicas produtivas locais da agricultura familiar.

Permanece um forte tropismo, uma verdadeira dependência de trilha das estruturas municipais e dos Estados. Por exemplo, o sistema administrativo, o financiamento e o arquivamento dos projetos no MDA funcionam ainda por Estado e não por território.

O segundo fator a limitar o efeito território é de ordem tecnocrática e profissional. O poder da rede sociotécnica dos agrônomos (MDA, secretarias de Agricultura, Emater, serviços do Incra, ONGs) é bastante potente para constituir um sistema de regulação mediante os objetos técnicos (plano, projeto, equipamentos, máquinas). Essa rede dos técnicos está marcada por dependências fortes do poder político e por alianças com os poderes locais, com os quais compartilham um certo autoritarismo e um sentimento de competência técnica com relação aos agricultores e à sociedade civil.

Este tropismo sociotécnico está sendo reforçado pela natureza dos investimentos e das ações financiadas: em 90\% são infraestruturas e equipamentos técnicos, mesmo quando as prioridades identificadas pelos diagnósticos, pelos planos ou pelos agricultores indicam ações para regularização fundiária, comercialização dos produtos, acesso ao financiamento, assistência técnica e formação.

Até hoje, o programa não dispõe de mecanismos de controle, de monitoramento ou de avaliação dos projetos, da sua 
aplicação e do seu uso. As primeiras propostas de monitoramento informatizado deixam a avaliação dos projetos e programas nas mãos dos agricultores, o que conduz a um conflito de interesses e de competências. Tal mecanismo de avaliação - ao confundir participação e fortalecimento das capacidades dos atores locais com as lógicas de desenvolvimento territorial - arrisca favorecer a emergência de projetos mal adaptados. Uma das fraquezas do PDSTR reside na associação sistemática entre participação popular e territorialização, quando os dois processos são bem distintos, com lógicas diferentes. Por outra parte, apesar de um real voluntarismo dos agentes do MDA/SDT e de verdadeiros avanços em termos de institucionalização do processo ligados à importância e urgências das necessidades locais, ao entusiasmo pioneiro e à mobilização dos movimentos sociais, outras dificuldades mais conjunturais aparecem na implementação da abordagem territorial.

\section{Dificuldades operacionais}

Primeiro, não basta criar espaços de diálogo abertos às organizações de agricultores quando elas não dispõem dos meios para elaborar e defender os seus projetos. Nos conselhos municipais, os agricultores não têm quase nenhum poder de decisão, pois as nominações dos conselheiros são, geralmente, realizadas pelo Poder Executivo (prefeituras) e as opiniões são apenas consultivas (Schneider et al., 2003).

Segundo, os volumes de financiamento de projetos do PDSTR são ainda muito limitados e com verbas anuais, o que leva a uma grande fragmentação de microrrealizações que dificilmente podem ter um impacto territorial. A implementação de projetos maiores e intersetoriais depende de articulações com vários ministérios e com os Estados. Tais projetos sofrem, então, das diferenças em termos de escala de ação, níveis e temporalidades de decisão entre as 
instituições e em termos de ritmo. Portanto, existe uma disparidade de prioridades entre os atores locais, os prefeituras municipais, os governos estaduais e o governo federal, ou, até entre os diversos ministérios.

Terceiro, a jovem Secretaria de Desenvolvimento Territorial do MDA não dispondo ainda de funcionários, tem que recorrer a consultores terceirizados, recrutados por períodos de 3 a 6 meses, renováveis, em vez de implementar recrutamentos seletivos por concurso (mesmo para contratos de duração determinada). O apoio aos territórios pode, portanto, sofrer dos efeitos perversos das consultorias. Por exemplo, a realização dos diagnósticos e dos planos depende de sistemas de financiamento mediante consultores externos remunerados por produto intermediário e não por tempo ou produto final. Para recuperar a sua remuneração, estes tendem a aplicar ao pé da letra, de maneira rígida a metodologia proposta, multiplicando produtos e relatórios intermediários, ignorando as realizações anteriores ou as dinâmicas locais especificas (Schneider et al., 2003; Tonneau \& Sabourin, 2007).

Como o MDA não dispõe de um corpo constituído de funcionários capacitados nem da capilaridade de representações locais nos Estados, sua ação depende muito de consultores externos, recrutados por outras entidades terceirizadas, muitas vezes por critérios de interconhecimento ou de afiliação política, o que não garante uma qualidade homogênea e neutra do processo de animação territorial.

De fato, o enfoque territorial só pode existir em função de processos de negociação alimentados por uma animação local, mesmo que ela possa ser fortalecida por apoios externos. Essa animação necessita de atores competentes, comprometidos e motivados, mas que não estejam ligados a interesses em conflito. Disto depende a 
sua legitimidade para poder construir a tomada de responsabilidade dos atores a partir de uma capacidade em reconhecer e em entender os outros e as suas posições (Tonneau \& Sabourin, 2006).

A intenção do MDA é promover um desenvolvimento territorial a partir de práticas de democracia participativa que implicam a participação de todos os setores envolvidos na elaboração e apropriação de um projeto comum, formalizado num plano. A maioria dos problemas vem, justamente, do déficit de projeto comum ou da capacidade para fazer emergir tal projeto. No momento, a prioridade setorial é dada ao apoio à agricultura familiar, segmento que, por natureza, não é objeto de muitos interesses nem de fortes polêmicas, fora o caso da reforma agrária (Sabourin, 2007).

Com a nova abordagem, as escolhas em matéria de equipamentos coletivos dependem do Conselho Territorial e não mais dos Conselhos Municipais de Desenvolvimento Rural (CMDR), acusados de não terem poder de decisão ou de serem facilmente manipulados pelos prefeitos. Mas a perda de poder dos executivos municipais não significa, portanto, que os agricultores familiares vão obter mais poder no novo conselho intermunicipal, pois tudo depende da capacidade das suas organizações em se mobilizarem e se coordenarem, para terem peso nas decisões e para adquirirem as competências para construir projetos comuns. No entanto, apesar de dificuldades iniciais de implementação, em parte devidas à falta de experiência, essas iniciativas prefiguram um novo campo de experimentação no Brasil, em termos de interação entre a ação coletiva das populações rurais e a ação pública do Estado nas suas diversas escalas. Em termos de impacto, o PDSTR é ainda pouco significativo: seu orçamento anual representa em torno de $\mathrm{R} \$$ 100 milhões, enquanto o Pronaf, com quase 10 bilhões aplicados em 2006, constitui a única política pública estruturante para a agricultura familiar brasileira. 


\section{Que balanço?}

Depois de apenas três anos de implantação de uma nova política, um balanço só pode ser parcial. Podemos perguntar se o enfoque territorial, além do efeito inovador dos conceitos e do vocabulário, não esconde apenas uma nova roupagem de velhas receitas, após as últimas abordagens do desenvolvimento rural: integrado, integral, apropriado, autocentrado, endógeno ou, mais recentemente, sustentável (Valencia \& Nolasco, 2006).

O exercício e a implementação dos conselhos municipais e territoriais representa um avanço com efeitos positivos em termos de possibilidade de aprendizagem para os agricultores familiares e as suas organizações. Pode-se duvidar da capacidade de efeito alavanca para o desenvolvimento. O estudo de Veiga (2006), focalizando as primeiras experiências territoriais em duas regiões do Rio Grande do Sul, indica que o desenvolvimento dependeu mais dos ativos iniciais da região (infra-estrutura e capital humano) do que do efeito dos apoios territoriais.

Vários fatores podem explicar essas dificuldades (Tonneau \& Sabourin, 2006):

- a assimetria de informação e de poder de decisão nos conselhos;

- os limites da democracia técnica e participativa e das competências dos conselheiros, assim como dos técnicos;

- a pulverização dos financiamentos, dos projetos e dos seus efeitos, ligada à fragmentação dos poderes;

- um enfoque do MDA e do Condraf ainda setorial, agrícola e limitado sobre a agricultura familiar;

- as dificuldades de coordenação entre os ministérios (entre eles e com os Estados) e as concorrências entre diversos espaços e poderes de planejamento; 
- os freios da Constituição brasileira: regime federal, pulverização do orçamento via um sistema de emendas entre 10.000 municípios, eleição a cada 2 anos;

- os limites cognitivos sobre a divisão regional e territorial, a fronteira entre rural e urbano (Veiga, 2002), como exemplificado pelo efeito polarizador e desestruturante da integração de grandes centros urbanos, inclusive capitais regionais, como Brasília (Águas Emendadas) ou Campina Grande (Borborema), no seio dos territórios rurais.

A principal limitação, pelo menos no Norte e Nordeste, vem também do fato que, nessas regiões, o Estado não chegou a assegurar os ativos e as infra-estruturas de base antes do apoio aos atributos específicos dos territórios, como foi o caso da política de recuperação regional na Europa (projeto Leader, por exemplo). No Brasil, as regiões que melhor podem aproveitar-se desses apoios específicos são aquelas que já disponham de infra-estruturas: os pólos irrigados, as bacias urbanas ou peri-urbanas dotadas de agroindústria, as zonas turísticas - ou seja, onde a agricultura familiar e camponesa já está marginalizada ou está sem trunfo competitivo frente às empresas agrícolas. Não são exemplos de territórios prioritários.

A experiência dos Conselhos Municipais de Desenvolvimento Ruraljámostrouaperversidadedavisãoneoliberal dadescentralização que leva a uma fragmentação dos poderes e contra-poderes locais, podendo contribuir para fragilizar antigos espaços de resistência ou de negociação historicamente e socialmente construídos. Em certos casos, na Amazônia, onde a institucionalidade está sempre mais frágil ou mais recente, a dinâmica territorial do MDA foi instrumentada por lutas internas entre sindicatos e movimentos para a representação dos agricultores familiares. No caso da região de Marabá (Pará), o processo chegou a destruir praticamente a organização anterior (Veiga et al., 2006). Em outras regiões (Acre, Mato Grosso), os projetos dos agricultores familiares encontram-se 
reféns da competição entre ONGs (Sabourin, 2006c). Nesse tipo de dialética de negação do outro e de concorrência entre ideologias, muitas vezes, é mais fácil e rápido destruir do que construir projetos comuns.

O futuro do enfoque territorial dependerá, sobretudo, da possibilidade de grupos subalternos da agricultura familiar e camponesa assegurarem, não apenas a sua representação, voz e poder de decisão nos conselhos, mas também de desenvolverem uma capacidade de relação com as comunidades locais e com outras instituições e de coordenação de projetos comuns.

Por natureza, a implementação de qualquer tipo de planejamento ascendente favorece a emergência e a formalização de novas demandas sociais e de novas alianças entre atores e setores. Pode também permitir que as diversidades regional, ambiental e cultural sejam melhor levadas em conta. Pode abrir possibilidades de conquista de espaços, ou, pelo menos, de janelas de negociação entre atores públicos e privados e entre ação coletiva e ação pública.

\section{Diversidade das agriculturas familiares e camponesas}

No debate em torno da dualidade da agricultura brasileira, a recorrência e a institucionalização de uma oposição exagerada entre agronegócio e agricultura familiar tendem a ocultar uma questão-chave: a do modelo de agricultura familiar. Esse debate essencialmente ideológico - como o mostram as estatísticas -, consegue, pela sua simplicidade maniqueísta, mobilizar e opor partidos políticos, movimentos sociais e governo. Trata-se de um falso debate, amplamente manipulado de uma e outra parte, já que esses dois segmentos contribuem, na sua maioria, para as mesmas cadeias. Mas o seu caráter, ao mesmo tempo populista e elitista, contamina o verdadeiro debate que termina sendo minoritário no seio do MDA e dos movimentos sociais, ou seja, aquele que 
deveria discutir uma política adaptada à diversidade das agriculturas familiares e camponesas do Brasil. Tal política só poderia ser diversificada e regionalizada ou descentralizada (Schneider, 2006), pois a tendência que se fortaleceu foi dar apoios produtivos aos agricultores capazes de se integrarem ao mercado capitalista e reservar um tratamento social (bolsa-família, ajuda alimentar) aos segmentos menos dependentes do mercado capitalista, por meio do combate à pobreza.

Pequena empresa familiar ou agricultura familiar $e$ camponesa diversificada?

Tal leitura tende a homogeneizar uma visão parcial da agricultura familiar, que, muitas vezes, está limitada aos Estados do Sul do país (Tonneau e Sabourin, 2006). Apaga a diversidade das situações locais em termos de estruturas, de capacidades de acesso aos mercados, ao crédito, à capacitação e à inovação, num contexto de abandono da educação rural e de falta de recursos da extensão rural. Subestima a fragilidade e as flutuações rápidas e freqüentes do mercado capitalista das grandes cadeias (leite, cereais, tubérculos, etc.). Ignora a herança de vários sistemas camponeses locais que garante ainda a reprodução das unidades familiares graças à autonomia (dos insumos externos, do mercado capitalista, dos financiamentos públicos) e a flexibilidade de adaptação às demandas de mercados diversificados ou de proximidade.

As estatísticas oficiais e os estudos sobre cadeias produtivas não levam em conta o papel do autoconsumo e da redistribuição não monetária e não mercantil na consolidação da segurança alimentar. Essa visão limitada ao mercado capitalista internacional ignora os efeitos positivos dos circuitos curtos (venda direta, feiras locais, mercados dos produtores e feiras agroecológicas) em termos de abastecimento e de alimentação de qualidade para a população das cidades, sobretudo as pequenas e médias. 
A influência do modelo europeu é forte, mas sem tirar dele as lições do processo de exclusão e de êxodo rural que caracterizou a modernização da agricultura familiar européia, apesar de um contexto bem mais favorável (anos 50-70). No entanto, a herança camponesa desse modelo é ignorada ou desprezada, quando, precisamente, um movimento de re campesinização está em curso, em vários países da União Européia (Ploeg, 2003, 2006; Auclair, 2006).

A tendência dos instrumentos de políticas públicas em favorecer esse modelo único de agricultura familiar, paradoxalmente, traz argumentos a favor da tese oposta, neoliberal e conservadora, que prega o tratamento social da agricultura familiar e camponesa chamada de marginal ou periférica (FAO-Incra, 1996) e dos semterra - para evitar as revoltas e os saques - mediante programas de combate à pobreza. Estes programas assistencialistas e segmentados em função do público-alvo (mulheres, jovens, velhos, nordestinos do semi-árido) têm por efeito transformar camponeses mais ou menos autônomos em cidadões de segunda classe, dependentes da ajuda alimentar e social.

Cada vez mais, sob a influência das agências multilaterais, as políticas públicas são concebidas de maneira segmentada, levando a uma disjunção entre políticas sociais e políticas produtivas contrária ao princípio tripartite do desenvolvimento sustentável (equilíbrio entre social, econômico e ambiental). Esses enfoques (previdência, aposentadoria rural, bolsa- alimentação, bolsa-família) reduzem o econômico ao princípio do acesso das populações rurais pobres (rural poors) ao mercado capitalista e mantêm sua dependência dos supermercados e das firmas agroalimentares, já não como produtores, mas como consumidores.

Um exemplo dessa visão aconteceu na primeira fase do projeto Fome Zero no marco do Ministério Extraordinário da Segurança Alimentar (MESA). A ação principal de ajuda alimentar 
no meio rural foi justificada pelo efeito induzido de dinamização da produção familiar e da economia local pela injeção de ajuda, já não in natura (cestas básicas), mas em dinheiro, como tinha acontecido com a aposentadoria rural (Delgado, 2000). Mas, os 50 reais mensais distribuídos às famílias pobres, diferentemente das pensões, não vieram em dinheiro, mas na forma de um cartão magnético de uso limitado aos supermercados conectados às redes bancárias. Essa medida só fez aumentar a compra de alimentos e produtos manufaturados provenientes da agricultura empresarial e não da produção local ou dos circuitos de proximidade.

Independentemente dos limites orçamentários e políticos que podem afetar a durabilidade desses programas sociais, quais serão as conseqüências desses presentes "envenenados" da sociedade aos pobres das zonas rurais? Em realidade, essa redistribuição do Estado passa pela mediação dos Estados, municípios, políticos locais, ONGs, tantas tutelas regionais e locais e tantas outras oportunidades de manipulação e de dependência.

Outro exemplo desse modelo - experimentado com o apoio do Banco Mundial - foi a chamada reforma agrária mínima ou pelo mercado. À parte o fracasso da sua aplicação, a proposta era, sobretudo, destinada a limitar o êxodo rural, a afastar os pobres dos centros urbanos e, eventualmente, nas zonas de grande agricultura, fornecer uma mão-de-obra barata às empresas agrícolas ou ainda às firmas agroalimentares trabalhando em integração. Foi, precisamente, o sistema de integração agricultura/indústria aplicado à produção de soja, suínos e aves que provocou a expulsão de milhares de pequenos agricultores dos Estados do Sul, levando à criação do MST.

As propostas deadaptaçãodeummodelodeproduçãocamponês renovado para a pequena agricultura familiar, pelo movimento Via Campesina, são defendidas no Brasil pelo Movimento dos Pequenos Agricultores (MPA). Essas propostas são principalmente adaptadas 
à realidade dos três Estados do Sul (Paraná, Rio Grande do Sul, Santa Catarina), onde nasceu o MPA. Elas têm dificuldade para serem difundidas em nível nacional porque o principal componente e porta voz da Via Campesina no Brasil é o MST (Porto-Gonçalves, 2005; Aubertin \& Pinton, 2006). Por um lado, se certos dirigentes nacionais do MST retomam alguns elementos desse discurso, suas práticas e doutrinas permanecem aquelas, contraditórias, do projeto de revolução socialista; mas, por outra parte, se as bases locais do MST fossem sensibilizadas por essas teses - que correspondem melhor aos seus projetos e práticas -, poderiam discutir a doutrina do movimento.

Cabe agora um esforço de construção científica e histórica das bases brasileiras de um projeto renovado de agricultura camponesa pela Via Campesina, que financia a realização de uma considerável publicação (5 tomos) sobre a história social do campesinato no Brasil. De fato, os germes do debate existem, assim como iniciativas alternativas.

\section{Que instrumentos e políticas fortalecer ou adotar?}

Cabe notar os esforços inéditos do Governo Lula em termos de apoio à agricultura familiar e ao desenvolvimento rural territorial. Os resultados dependem agora da durabilidade de perspectiva doravante ofertada pelo segundo mandato. Uma crítica responsável deve propor alternativas ou, pelo menos, pistas de pesquisa para experimentá-las. Considero a proposta de três temas formulados a partir de minhas pesquisas, de referências internacionais, e, também, de iniciativas locais ou de experimentos em curso no País.

Para uma agricultura familiar e camponesa mais autônoma

A simples observação e análise das diversas formas da agricultura familiar (Schneider, 2006) e da importância da herança 
camponesa no Brasil rural do século XXI (Carvalho, 2005) chamam a atenção para um reconhecimento pelas políticas públicas de situações e de sistemas de produção diferenciados. O leque desses modos de produção vai da agricultura de subsistência até a pequena empresa familiar diversificada, passando por diversas situações intermediárias, por exemplo: a dominante camponesa, ou, ao contrário, as mais integradas ao mercado, ou, ainda, aquelas marcadas pela importância oculta da pluriatividade (Schneider, 2003).

Essa diversidade vital supõe instrumentos que possam também contribuir para a reprodução de unidades baseadas no autoconsumo e na venda local de excedentes. Algumas propostas já foram formuladas na análise do Pronaf e do Pronat. Trata-se de apoiar sistemas de produção mais autônomos, menos dependentes do mercado capitalista e de insumos externos, e, portanto, melhor adaptados a certas situações econômicas ou geográficas e a sistemas mais rústicos para garantir a reprodução de unidades familiares viáveis.

Outro eixo de política de desenvolvimento rural passa pelo reconhecimento e pelo apoio aos dispositivos coletivos de agricultores assegurando, gratuitamente, a gestão de recursos comuns (biodiversidade e sementes, terras e floresta, pastagens e áreas de extrativismo, águas, etc.) ou a produção de bens públicos: informação, capacitação, inovação, etc. Tal enfoque constituiria uma política original de apoio à multifuncionalidade da agricultura e do espaço rural adaptada aos países do Sul (Sabourin, 2006a, 2007).

Comercialização e qualificação dos produtos

O potencial de conquista sustentável de mercados especializados em nichos pelos agricultores familiares foi amplamente exagerado. Por outra parte, quando políticas de apoio foram implementadas, elas foram captadas ou desviadas por agricultores 
patronais. A autonomia passa também pela diversificação das relações de mercado e de produção.

A verdadeira diversificação passa pela identificação e pela promoção da diversidade dos mercados potenciais, locais, de proximidade, regionais, nacionais... e, sobretudo pela diversidade das modalidades de acesso aos consumidores. Neste sentido, fala-se de construção social desses mercados: venda direta, venda na roça, feiras, dias de festa por produto típico, venda às cooperativas de consumo, etc.

O conjunto dessas práticas tem a característica comum de reduzir o efeito da concorrência capitalista. Trata-se, em todos os casos citados, de mercados natural, social ou geograficamente protegidos e territorializados.

Entretanto, nada impede o Estado de criar mercados internos politicamente protegidos. É o caso dos mercados públicos e institucionais de produtosalimentarespara os hospitais, os restaurantes e a merenda das escolas que podem ser implementados em escala federal, estadual, municipal ou territorial. Uma experiência federal exemplar neste sentido está, paradoxalmente, sendo conduzida no marco do MAPA pela Conab, em associação com o programa Fome Zero administrado pelo Ministério do Desenvolvimento Social (MDS).

O Programa de Compra Antecipada de Alimentos (PAA), em princípio reservado aos agricultores familiares, constitui, apesar de recursos ainda muito limitados (teto de 2.500 reais por família/ ano), um verdadeiro instrumento adaptado ao fortalecimento da agricultura familiar e camponesa.

Os processos de qualificação dos produtos agrícolas em função da origem, do processamento ou de especificidades locais, também constituem modalidades de diferenciação e de redução dos efeitos 
da concorrência, além de permitirem criar mercados territorializados associando relações de intercâmbio e de reciprocidade (Sabourin, 2006b). No entanto, o modelo atual considera - sobretudo nos processos de qualificação dos produtos -, as possibilidades de certificação para acessar novos nichos, se possível para a exportação. Um modo mais democrático é a certificação gratuita, que não encarece os custos de produção. Ela é adaptada à agricultura familiar, e, obviamente, não pode ser confiada a empresas capitalistas, mas às organizações de agricultores. Iniciativas já existem no sul do País, com a certificação chamada participativa ou de grupo (Medaets \& Medeiros, 2004), ou com certificação mútua ou comunitária nas feiras agroecológicas da Paraíba (Sabourin et al., 2005b; Tonneau \& Sabourin, 2007).

Diversificação dos instrumentos de redistribuição fundiária

Diversas propostas alternativas foram estudadas (Silva \& Del Grossi, 2000), mas não foram retomadas pelas organizações sindicais e pelo MST que, ao contrário, aceitaram negociar com o último governo uma certa co-gestão da reforma agrária.

No entanto, existe um campo pouco explorado de modalidades de ação, como a regularização fundiária, hoje possibilitada pelas técnicas de cadastro por sensoriamento remoto ou de sistemas geográficos de informação.

Outra questão recorrente é aquela da atribuição de títulos aos ocupantes legítimos em situação precária, como os posseiros e os quilombolas, mas também aos usuários de fundo de pasto ou de reservas extrativas. Faz falta um verdadeiro estatuto das cooperativas de serviços da agricultura familiar, mas, ainda mais urgente, seria um estatuto do arrendatário e do meeiro (com controle público do aluguel da terra). Certas competências da reforma agrária poderiam ser descentralizadas para os Estados e municípios sob controle 
federal. Poderia ser estudada a constituição de sociedades fundiárias mistas, associadas ao crédito fundiário - do tipo das Sociétés d'Amenagémente Foncier et d'Establissement Rural (Safer), na França - ou de formas de agricultura de grupo para facilitar os processos de transição entre gerações ou para os projetos coletivos em situação de reforma agrária - do tipo dos Grupos de Agricultores em Comum (GAEC), na Europa.

\section{Conclusão}

A análise dos debates em matéria de agricultura e de desenvolvimento rural considera, sobretudo, a crítica a uma falsa oposição entre um agronegócio superavaliado e uma agricultura familiar majoritária que vê a sua real contribuição econômica ocultada. Esse quadro não é exaustivo, pois não trata da política de reforma agrária. O principal debate sobre o modelo de reforma agrária - acesso à terra por distribuição (e desapropriação) ou acesso à terra pelo mercado, mediante crédito fundiário - ocultou, de fato, as verdadeiras questões em matéria de desconcentração e de redistribuição fundiária.

Existe, também, um debate transversal em torno da questão da autorização e do controle da produção baseada em Organismos Geneticamente Modificados (OGM) que supera o quadro do MDA, e no qual este Ministério e o do Meio Ambiente (MMA) - desfavoráveis ao uso de OGM, mas minoritários - se opõem aos outros ministérios envolvidos: Agricultura, Desenvolvimento, Indústria e Comércio, Ciência e Tecnologia, Relações Exteriores. Sob a pressão de firmas transnacionais (Monsanto, Cargill, etc.), a autorização dos OGM foi votada sem chocar a opinião pública graças a um subterfúgio: uma lei global de biossegurança reuniu num só pacote a pesquisa genética, a produção de células troco por razões de saúde humana e a produção agrícola de OGM. 
Enfim, cabe notar a ausência de descentralização dos debates e de um verdadeiro debate nacional sobre questões tão essenciais para o Brasil e para as gerações futuras: a redistribuição fundiária, o uso dos OGM, as alternativas de mercado ao mercado de intercâmbio capitalista.

\section{Nota}

1 Os usineiros da cana-de-açúcar foram tratados como heróis da nação em discurso recente do presidente Lula.

Which public policy for family agriculture in the second administration of President Luis Inácio Lula da Silva?

Abstract: President Lula da Silva government still gave resources priority to agribusiness despite the important increase of funding destined to family and peasant agriculture. How to explain what it seems as a contradiction and, over all, to which kind of debates inside the federal government answer these positions? The article analyzes the tensions, advances and impasses of the first government Lula in terms of family agriculture and rural development policies, based on the application of its mains instruments: the National Support Program for Family Agriculture and the Program for Sustainable Development os Rural Territories.

Keywords: Brazil, globalization, government Lula, public policies, family agriculture, rural development.

\section{Referências}

ABRAMOVAY, Ricardo. Desenvolvimento rural territorial e capital social. In: SABOURIN, E.; TEIXEIRA, O. (Eds.). Planejamento e desenvolvimento dos territórios rurais: conceitos, controvérsias e experiências. Brasília: UFPB, CIRAD, Embrapa, 2002. p. 113-128. 
ABRAMOVAY, Ricardo. Representatividade e inovação. In: SEMINÁRIO NACIONAL DE DESENVOLVIMENTO RURAL SUSTENTÁVEL. Brasília: MDA, Condraf, 2005.

ABRAMOVAY, Ricardo; PIKETTY, Marie Gabrielle. Politique de crédit du programme d'appui à l'agriculture familiale (Pronaf): résultats et limites de l'expérience brésilienne dans les années 1990. Cahiers Agricultures, v.1, n. 14, p. 25-29, 2005.

ABRAMOVAY, Ricardo; VEIGA, José Eli da. Novas instituições para o desenvolvimento rural: o caso do Programa de Fortalecimento da Agricultura Familiar (Pronaf). Brasília: Fipe, Ipea Nacional, 1999. (Texto para Discussão, n. 641).

AUBERTIN, Catherine; PINTON, Florence. Les paysans: figure emblématique du développement durable? In: AUCLAIR, L.; ASPE, C. ; BAUDOT, P. (Dir.). Le retour des paysans? Á l'heure du développement durable. Aix-en-Provence: IRD-EDISUD, 2006. p. 15-29.

AUCLAIR, Laurent. Introduction. In: AUCLAIR, L.; ASPE, C. ; BAUDOT, P. (Dir.). Le retour des paysans? À l'heure du développement durable. Aix en Provence: IRD-EDISUD, 2006. p. 7-12

BRASIL. MINISTÉRIO DE DESENVOLVIMENTO AGRÁRIO (MDA). Conselho Nacional de Desenvolvimento Rural Sustentável. Referências para um desenvolvimento territorial sustentável. Brasília: MDA/SDT, CONDRAF, 2003.

. Marco Referencial para Apoio ao Desenvolvimento de Territórios Rurais. Brasília, MDA/SDT, 2005a.

. Referências para uma Estratégia de Desenvolvimento Rural Sustentável. Brasília: MDA, 2005b.

CARNEIRO, Maria José. Política pública e agricultura familiar: uma leitura do PRONAF. Estudos Sociedade e Agricultura, n. 8, p.70-82, 1997.

CARON, P.; SABOURIN, E. (Coord.). Paysans du Sertão: mutations des agricultures familiales dans le Nordeste du Brésil. Montpellier: Cirad, 2001. (Coll. Repères). 
CARVALHO, Horacio de. O campesinato no século XXI: possibilidades e condicionantes do desenvolvimento do campesinato no Brasil. São Paulo: Vozes, 2005.

DELGADO, Guilherme; CARDOSO JUNIOR, José Carlos. Universalização de direitos sociais mínimos no Brasil: o caso da previdência rural nos anos 90. In: CONGRESSO MUNDIAL DE SOCIOLOGIA RURAL, 10., 2000, Rio de Janeiro. Anais. 2000. CDRom.

DELGADO, Guilherme; JÚNIA, Conceição; JADER, José de Oliveira. Relatório de avaliação do Programa de Acquisição Anticipada de Alimentos (PAA). Sociedade e Desenvolvimento Rural, n. 0, p. 18-39, 2007.

DUQUE, Ghilaine; DINIZ, Paulo César Oliveira. Intervenção da sociedade civil organizada com e para a agricultura familiar no Nordeste semiárido: experiência da Articulação do Semi-Árido. In: CONGRESSO BRASILEIRO DE SOCIOLOGIA, 11., 2003, Campinas. Anais. Campinas: Unicamp, 2003.

FAO/INCRA. Perfil da agricultura brasileira. Brasília, Instituto Nacional de Colonização e de Reforma Agrária, 1996. (Convênio IncraFAO).

FAO/INCRA. Novo retrato da agricultura familiar: o Brasil redescoberto. Brasília, DF, 2000. (Projeto FAO/BRA 036).

IBASE. Avaliação dos programas de geração de emprego e renda. Democracia Viva [revista], Edição Especial, 1999.

IBGE. Censo agropecuário, 1995. Rio de Janeiro: IBGE, 1996.

INCRA. Novo mundo rural: projeto de reformulação da reforma agrária. Brasília: MDA-INCRA, 1999.

MEDAETS, Jean Pierre; MEDEIROS, Joseimar Xavier. A ação coletiva no controle da qualidade da produção orgânica familiar: análise comparativa entre a certificação por auditoria externa e a certificação participativa em rede. In: CONGRESSO DA SOCIEDADE 
BRASILEIRA DE ECONOMIA E SOCIOLOGIA RURAL (SOBER), 42., 2004, Cuiabá (MS). Anais... 2004.

NETO, Graziano Francisco. Recolocando a questão agrária. In: STÉDILE J. P. (Org). A questão agrária hoje. Porto Alegre: Ed. UFRGS, 2002. p 238-254.

PLOEG, Jan Douwe van der. The virtual farmer: past, present and future of the Dutch peasantry. Assen (Países Baixos): Royal Van Gorcum, 2003.

. O modo de produção camponês revisitado. In: SCHNEIDER, S. (Org.). A diversidade da agricultura familiar. Porto Alegre: Ed. UFRGS, 2006. p 13-54.

PORTO-GONÇALVES, Carlos Walter. A nova questão agrária e a reinvenção do campesinato: o caso do MST. Revista OSAL, n. 16, 2005. Disponível em: <http://osal.clacso.org/dev/article.php3?id_article $=109>$.

SABOURIN, Eric. Conseqüências metodológicas e epistemológicas do reconhecimento da multifuncionalidade da agricultura. Estudos Sociedade e Agricultura, v.13, n. 2, p. 161-189, 2006a.

. Práticas sociais, políticas públicas e valores humanos. In: SCHNEIDER, S. (Org.). A diversidade da agricultura familiar. Porto Alegre: Ed. UFRGS, 2006b. p. 108-132.

Interação entre políticas públicas e dinâmicas locais da agricultura familiar do Território do Portal da Amazônia - MT. Brasília: UnB, Cirad, WWF, Projeto Diálogos, 2006c.

. Paysans du Brésil: entre échange marchand et réciprocité. Paris, França: Quae, 2007.

SABOURIN, Eric et al. Reconnaissance publique des acteurs collectifs de l'agriculture familiale au Nordeste. Cahiers Agricultures, v. 14, n. 1, p. 111-116, 2005.

SABOURIN, Eric et al. Développement durable et organisations des agriculteurs au Nordeste du Brésil. In: SEMINAIRE SOCIETE FRAN- 
ÇAISE D'ECONOMIE ET SOCIOLOGIE RURALE, Montpellier, SFER, ENSAM, CIRAD, 5-7/11/2005.

SCHNEIDER, Sergio. Pluriatividade na agricultura familiar. Porto Alegre: Ed. UFRGS, 2003.

SCHNEIDER, Sergio (Org.). A diversidade da agricultura familiar. Porto Alegre Ed. UFRGS, 2006.

SCHNEIDER, Sergio; SILVA, Marcelo Kunrath; MORUZZI, Marques Paulo. Políticas públicas e participação social no Brasil Rural. Porto Alegre: Ed. UFRGS, 2003.

SIDERSKY, Pablo. Reproductibilité de l'agriculture familiale dans l'Agreste de l'État de Paraíba, Brésil: dynamiques sociales, organisations locales, innovations techniques et sociales. Tese (doutorado) - University of Wageningen, 2006.

SILVA, José Graziano da. A modernização dolorosa. Rio de Janeiro: Zahar, 1982.

. O desenvolvimento do capitalismo no campo brasileiro e a reforma agrária. In: STÉDILE, J. P. (Org.). A questão agrária hoje. Porto Alegre: Ed. UFRGS, 2002. p 137-143.

SILVA, José F. Graziano da; DEL GROSSI, Mauro. Estimativas das famílias sem terra no Brasil: priorizando o combate à pobreza e ao desemprego: relatório final. Campinas: Unicamp, NEAD, 2000.

TONNEAU, Jean Philippe; SABOURIN, Eric (Org.). Agricultura familiar, políticas públicas e dinâmicas locais. Porto Alegre: Ed. UFRGS, 2006.

VALENCIA, Mireya; NOLASCO, Danilo. El papel de las organizaciones rurales y actores sociales en el enfoque territorial en Colombia: un nuevo rótulo para una antigua idea. In: SABOURIN, E (Org.). Associativismo, cooperativismo e economia solidária no meio rural. Brasília: UnB, Neagri, 2006. p. 210-240 (Cadernos do CEAM, 23).

VEIGA, Ira; OLIVEIRA, Myriam; BENTES, Francineide. Políticas públicas e dinâmicas locais da agricultura familiar no sul e sudeste 
do Pará. In: TONNEAU, J. P; SABOURIN, E. (Org.). Agricultura familiar, políticas públicas e dinâmicas locais. Porto Alegre: Ed. UFRGS, 2006.

VEIGA, José Eli da. O Brasil rural ainda não encontrou seu eixo de desenvolvimento. Revista Estudos Avançados, v. 15, n. 43, p. 101-119, 2001.

. Cidades imaginarias: o Brasil é menos urbano do que se calcula. São Paulo: Ed. Autores Associados, 2002.

Articulações intermunicipais para o desenvolvimento rural. In: SABOURIN, E. (Org.). Associativismo, cooperativismo e economia solidária no meio rural. Brasília: UnB, 2006. p. 221-278. (Cadernos do CEAM, n. 23). 